\title{
A grooved glass surface-plate for making a flat polished surface
}

\author{
Isoji Miyagi*
}

\begin{abstract}
To obtain a flat polished surface for microchemical analyses such as EPMA, SIMS, and ATR micro-FTIR, a glass plate with a grooved surface was developed for hand polishing with an abrasive film. It eases the polishing process by minimizing slipping or sticking, and results in negligible relief in the sample surface.
\end{abstract}

Keywords: EPMA, SIMS, ATR micro-FTIR, Polished sections, Surface-plate

\section{Introduction}

The flatness of the polished surface is important in the preparation of samples for microanalysis by techniques such as EPMA, SIMS, and ATR micro-FTIR, which are essential techniques in the quantitative analysis of geological samples. Conventional polishing techniques involve final buffing with a cloth, which leads to undesired relief that develops on the polished surface near the boundaries of relatively soft and hard materials, for example soft glass inclusions in hard quartz phenocrysts and hard glassy ash particles mounted in soft resin. While the unevenness is essential for the examination, identification, and textural interpretation of ore minerals using the reflected light microscope (Craig et al. 1981), such unevenness may interfere with successful analysis with either micro-FTIR spectroscopy (Lowenstern and Pitcher 2013) or the electron microprobe (e.g., Lengauer et al. 1997). The method of hand polishing described here uses a newly developed glass plate with a grooved surface that greatly aids in achievement of a flat polished surface.

\section{Conventional polishing techniques}

Conventional polishing techniques use either a polishing cloth or an abrasive film on a flat surface-plate. While soft material tends to wear down, hard materials endure the abrasion. The flexibility of the polishing cloth causes it to follow, and so accentuate, the resulting surface

\footnotetext{
*Correspondence: miyagi.iso14000@aist.go.jp Geological Survey of Japan, 1-1-1-7 Higashi, Tsukuba, Ibaraki 305-8567, Japan
}

difference between hard and soft materials. As a result, unevenness develops on the polished surface (Fig. 1). An abrasive film is more rigid than a cloth and so does not follow the surface differences between different materials. However, direct interaction between the flat abrasive film and the flat polishing surface can result in sticking (Fig. 2a), or a thin fluid film between the polishing surface and the abrasive film can cause the abrasive film to slip (Fig. 2b). Because of these problems, the abrasive film was hardly used for finishing.

\section{Grooved glass surface-plate}

The newly developed glass surface-plate allows ideal interaction between the flat polishing surface and an attached abrasive film (Fig. 3). The surface-plate prototype itself is approximately 200 by 300 and $8 \mathrm{~mm}$ thick (Fig. 4a). The top of the plate contains grooves that are $<100 \mu \mathrm{m}$ deep and $4 \mathrm{~mm}$ wide along the entire length of the plate. The grooves are separated by ridges $3 \mathrm{~mm}$ across (Fig. 4b, c). Sample size should be larger than threefold the spacing of grooves. The depth of the grooves can be shallower; empirically, $25 \mu \mathrm{m}$ is enough. A polishing film (e.g., diamond-impregnated film Suzuko POLYMOND, alumina-coated film 3M Scotch wrapping film sheet) is stuck to the wet glass plate like a suction cup. The rigidity of the abrasive film reduces the impact of the variation in hardness of phases within the sample. The grooves prevent the formation of a film of polishing fluid (water) and also provide channels for egress of waste particles. Flat ridges between the grooves give a flat polishing surface. Although the use of grooved cast-ion, 


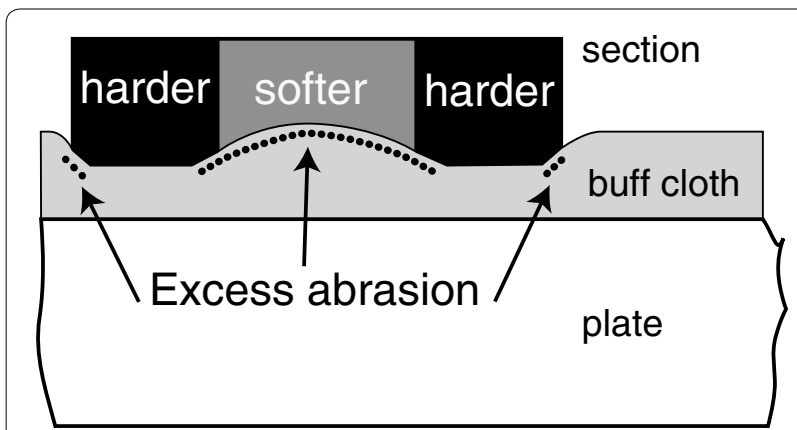

Fig. 1 Conventional polishing and relief that can develop as a result of use of a traditional buff cloth (cross section)

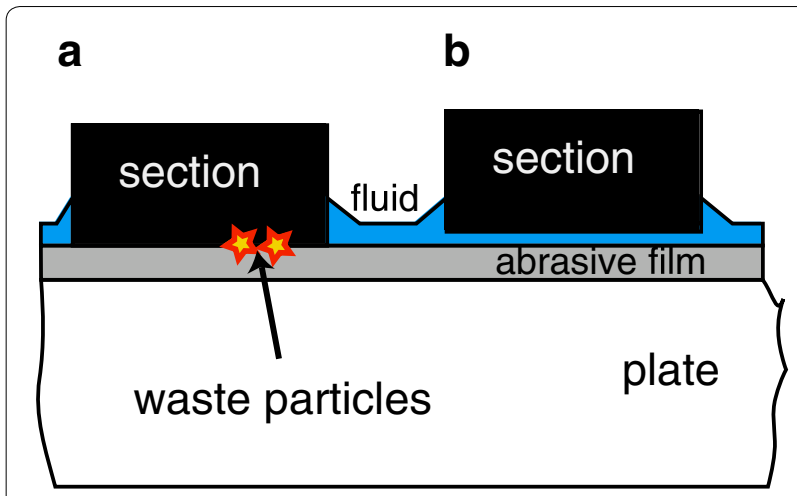

Fig. 2 Polishing with abrasive film on a adhered to a flat surface (cross section). Star indicates sticking or scratching

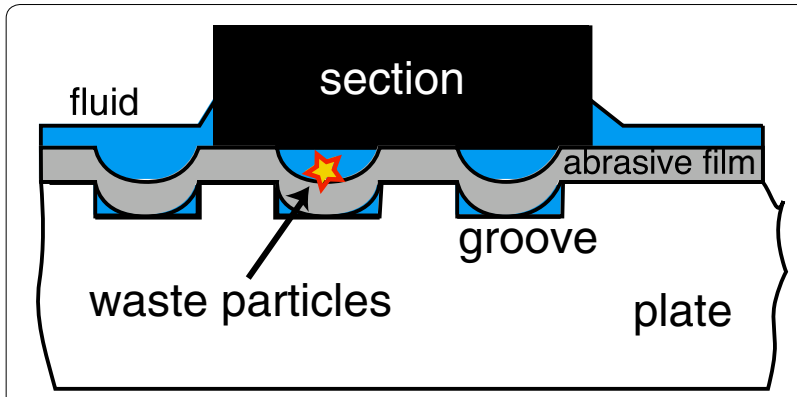

Fig. 3 Polishing with abrasive film on the grooved glass surface-plate (cross section). This system prevents fluid build-up between sample and polishing material and provides optimal contact

copper, or lead laps also allows preparation of excellent relief-free sections (Craig et al. 1981), they require constant resurfacing.

The grooves on a glass surface can be made by etching using dilute hydrofluoric acid on a masked float glass plate by a trained chemist. Shallow grooves can also be drilled into a hard metal such as bronze, in lieu of using glass. Plates with the listed specification are also available

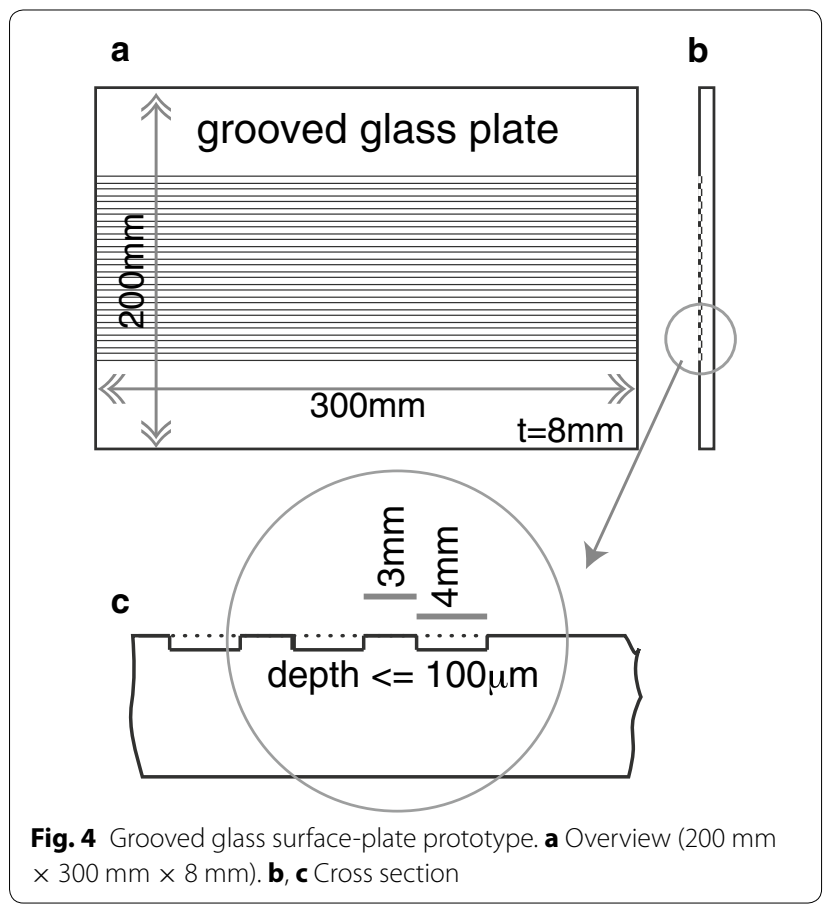

commercially from a Japanese dealer (Tsukuba-hikarikagaku Co, Ltd; Product No. TH-025; FAX: +81-29-8514696; WWW: http://t-h-k.jp).

\section{Efficiency}

The grooved surface-plate allows a flat polished surface even if the sample comprises both relatively hard and soft materials (Fig. 5). The flat surface encourages ideal

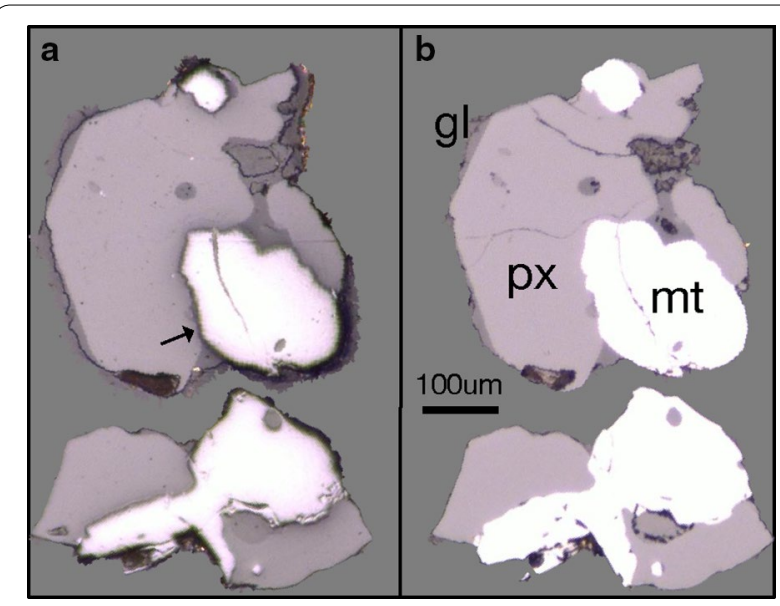

Fig. 5 Comparison of optical microphotographs. a Polished surface using conventional buff. b Re-polished surface using grooved glass surface-plate. $m t$ magnetite. px pyroxene. gl matrix glass. An arrow Rounded edge of magnetite 
contact between the flat sensor head of ATR micro-FTIR and the polished surface. As a side effect, the flat surface requires more effort to locate melt inclusions in goldcoated phenocrysts when using a reflected light microscope imaging. However, inclusions should be easily found with backscatter imaging, which is not affected by sample relief.

\section{Acknowledgements}

I thank Dr. N. Hoang for help in making a prototype surface-plate, Dr. J. B. Lowenstern for encouragement and for reading an early draft of the manuscript, two anonymous reviewers for their constructive comments, and Prof. Nakagawa for handling this paper.

\section{Competing interests}

The present study was supported by the National Institute of Advanced Industrial Science and Technology (AIST) of Japan, who holds a patent relating to the content of the manuscript. The author has no competing financial interests or personal interests which may have impacted the interpretation of the presentation of this information. The authors declare that they have no competing interests.
Received: 14 September 2016 Accepted: 8 December 2016

Published online: 03 January 2017

\section{References}

Craig JR, Vaughan DJ, Hagni RD (1981) The preparation of samples for ore microscopy. Ore microscopy and ore petrography, Wiley New York. ISBN: 0-471-55175-9

Lengauer W, Bauer J, Bohn M, Wiesenberger H, Ettmayer P (1997) Electronprobe microanalysis of light elements in multiphase diffusion couples. Mikrochim Acta 126:279-288

Lowenstern JB, Pitcher BW (2013) Analysis of $\mathrm{H}_{2} \mathrm{O}$ in silicate glass using attenuated total reflectance (ATR) micro-FTIR spectroscopy. Am Miner 98:1660-1668

\section{Submit your manuscript to a SpringerOpen ${ }^{\odot}$ journal and benefit from:}

- Convenient online submission

- Rigorous peer review

- Immediate publication on acceptance

- Open access: articles freely available online

- High visibility within the field

- Retaining the copyright to your article 